\title{
RECOMMENDATION PATTERN PREFERENCES AND SHARE ANALYSTS BIAS ON THE JSE
}

\author{
R. Lötter ${ }^{a *}$ and E. vd M. Smit
}

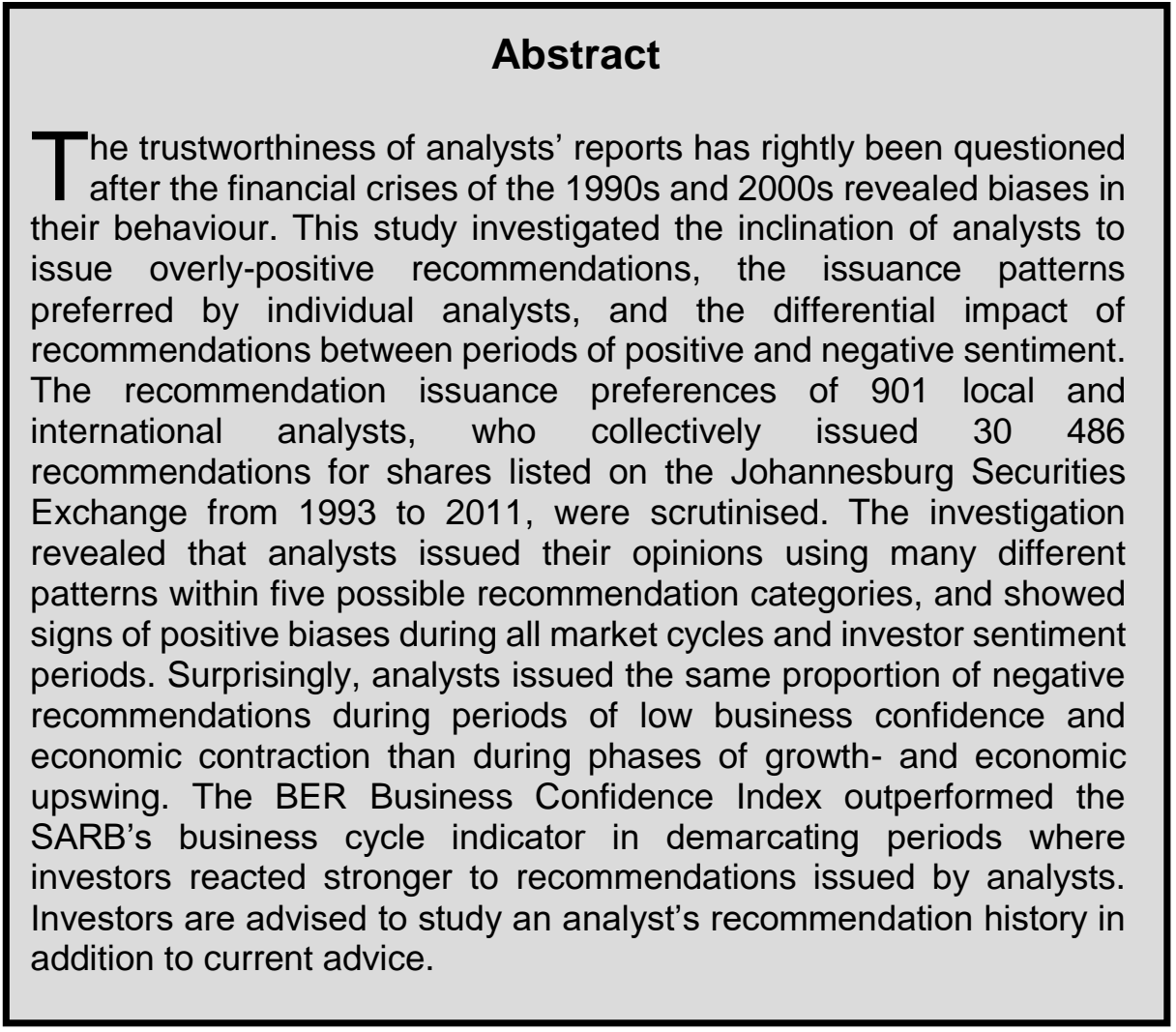

\section{Introduction}

A variety of investors trust financial analysts to interpret potentially complex financial information and then to distribute the information and their associated conclusions. The level of reliance on analyst recommendations is often related to the

\footnotetext{
* a Department of Business Management, Stellenbosch University, Private Bag X1, Matieland, 7602, South Africa

${ }^{b}$ University of Stellenbosch Business School, P O Box 610, Bellville, 7535, South Africa

Email: rlotter@sun.ac.za
} 
size and vocation of the investor; with smaller, non-professional investors having a tendency to over-rely on published recommendations (Malmendier \& Shanthikumar, 2007). These smaller investors also generally trade more and benefit less from issued recommendations when compared to their larger counterparts; regularly generating an inferior level of return when responding to recommendation upgrades and buy recommendations (Mikhail, Walther \& Willis, 2004).

While a large body of research supports the notion that analyst recommendations can have a significant impact on prices and contain value for investors in both developed markets (Stickel, 1995; Womack, 1996; Barber, Lehavy, McNichols \& Trueman, 2001; Boni \& Womack, 2006) and in emerging markets (Moshirian, Ng \& Wu, 2009; Gerritsen \& Lötter, 2014), analysts are not always influential (Loh \& Stulz, 2011) and some analysts have a greater impact on prices than others (Fang \& Yasuda, 2014). Investors therefore cannot expect all analysts to always give profitable advice and need to find a way of deciding which analysts to trust because they are not equally skilled (Welch, 2000).

Aside from variations in skill, one behavioural phenomenon in particular is often associated with analysts in the wider body of literature: a positive bias (Diefenbach, 1972; Stickel, 1995; Barber et al., 2001; Cowen, Groysberg \& Healy, 2006). Analysts who are overly positive, for instance, will issue buy recommendations instead of holds, and hold recommendations instead of sells. A positively-biased recommendation is therefore roughly defined in this study as a recommendation that should have been of a lower recommendation category.

The purpose of this article was to first identify whether analysts issuing recommendations for shares listed on the Johannesburg Stock Exchange (JSE) demonstrated a general tendency to be overly positive. The overall recommendation tendencies during periods of positive and negative sentiment were also investigated and the recommendation patterns amongst analysts were identified. Lastly, the abnormal impact of recommendations during (i) periods of high and low business confidence and (ii) expanding or contracting economic cycles was compared to investigate if investor sentiment was aligned with the impact of recommendations.

The remainder of this paper presents literature contextualising the individual analysts' recommendations relative to the factors that may influence their decision making processes. The methodology section describes the research process applied to measure the various analysts' recommendation reporting preferences and their impact on share prices. The results and discussions are presented and the study concludes with a discussion of the implications of the results for investors relying on analyst recommendations. 


\section{Literature review}

\subsection{Recommendations that impacted specific companies}

While not all analyst recommendations are associated with significant abnormal returns (Stickel, 1995; Mikhail et al., 2004), the impact of recommendations can be considerable. For instance, during 2007 Kenneth Bruce reported to Merrill Lynch regarding a leading mortgage lender's ability to continue doing business during the credit crisis. The report caused a 13 per cent fall in the share price on the day the report was issued. Another example was Meredith Whitney's downgrade of Citigroup, after which a fall of 6,9 per cent in the share price, the CEO's resignation, and even death threats against her followed (Loh \& Stulz, 2011). In both cases the analyst's opinion was respected by market participants. Loh and Stulz suggested that significant abnormal returns following a recommendation revision revealed the analyst's ability to occasionally change the perception of a company, and bring forth a 'paradigm shift'. When a single analyst changes the consensus opinion by issuing an influential recommendation, the 'paradigm shift' normally initiates other analyst recommendation revisions and traded volume increases.

The fall of Enron at the end of 2001 demonstrated another element of analyst behaviour. Two months before Enron filed for bankruptcy in December 2001, seventeen analysts were actively covering the company. Of the seventeen analysts, ten issued strong buy recommendations, while another five issued buy recommendations. What makes this noteworthy is that these favourable recommendations were published during the period where a 50 per cent loss in market capitalisation occurred and large accounting losses were reported for Enron (Clarke et al., 2006). The positively biased analysts subsequently encouraged doubt amongst investors concerning analysts' credibility when investors became aware that analysts had negative information without adjusting their recommendations accordingly. The question remains as to what influences analysts to change their recommendations?

\subsection{Factors influencing analysts' opinions}

Analysts are reported to react to both financial and non-financial information, or alternatively to both qualitative and quantitative information. Upcoming mergers and the release of annual financial data were identified as financial trigger events leading to recommendation revisions. That said, non-financial information is reported to often be of greater importance to sell-side analysts. Analysts were found to revise recommendations and change earnings forecasts after management teams released official statements, after adjustments in the strategic positioning of companies are 
made and after news affecting a company's operating environment is released (Kerl et al., 2012).

Further evidence suggests that the size and market share of a company, a company's product offering and the business environment that the company is competing in are taken into account when analysts issue recommendations (Previts et al., 1994). On the other hand, analysts have also been noted to have the ability to be side-tracked because of paying too much attention to macro factors and neglecting a company's specific information (Peng \& Xiong, 2006). Bradshaw (2002) found that analysts often justify negative recommendations by stating qualitative information, while positive recommendations are frequently based on more pragmatic valuations.

The relationship between the analysts and company management can also affect the views of analysts. Irvine $(2001 ; 2004)$ noted that the types of information content released by analysts are influenced by the trading commissions they might receive from increased traded volumes. Furthermore, analysts are often provided with information by the management personnel of companies, and this close relationship can have an effect on the informational content of analyst publications. Clarke et al. (2006) noted that the analysts are often employed by investment banks that might own the shares within the coverage of the analyst. This scenario clearly puts the analysts in a position to favourably affect the banks' portfolios, creating a situation where "analysts are reluctant to issue negative recommendations because of the potential loss of future investment banking deals" (Clarke et al., 2006:2).

\subsection{The reaction of market participants to new information}

After new information or recommendations are released by analysts, individual and institutional investors have to interpret the information and physically trade shares in order to change a share's price. Prices normally fluctuate after information reaches investors, because investors have non-uniform ways of interpreting information and a variety of processes and incentives to act upon the information according to the 'differences of opinion' theory (Harris \& Raviv, 1993). The differences in investors' decision-making models are a double-edged sword: it creates the much needed liquidity offered by counterparties who buy (sell) when others are selling (buying), but may also cause severe short-term price fluctuations, wrongful over- and underpricing of assets, and market-'bubbles' (Shefrin, 2000). Investors' sentiment, the type of information, and how the information reaches investors, also play a role in the effect that information has on prices.

Savor (2012) investigated the effect of information-based price movements versus price movements not associated with analyst reports or new financial data. Savor concluded that strong price movements that do not coincide with at least one credible 
analyst report to support the price change had strong price reversals, while price events accompanied by sufficient supporting information were normally followed by sustained price momentum. An analyst's report or various analysts' reports had to be aligned with the direction of the price change; otherwise a strong price reversal had a high probability of occurring. Loh and Stulz's (2011) US study revealed that more than one third of all recommendations issued did not result in the advised pricechange direction or 'sign', meaning a plus or minus to positive and negative recommendations respectively.

Any single analyst will naturally have difficulty issuing recommendations for all the listed shares. The consequence is specialisation and focus on certain industries or companies. Boni and Womack (2006) implemented an industry-centred research methodology for the 1996 to 2001 time period, and found that 53 out of 59 industries yielded significant one-month abnormal returns when shorting sell-recommended shares and purchasing buy-recommended shares. Boni and Womack (2006:1) also found that recommendation changes for shares covered by many analysts yielded substantially less returns than shares followed by fewer analysts. The conclusion reached was that "competition among analysts reduces the opportunity to profit". Analysts who can operate in a niche environment covering a lesser-known industry or small shares might have an advantage over analysts who cover well-known or favoured shares.

\subsection{Positive bias and impact}

Analysts have often been reported to issue overly-positive recommendations (Diefenbach, 1972; Stickel, 1995; Barber et al., 2001) to increase investors' trade activities (Prayag \& Van Rensburg, 2006:7) or protect their affiliations (Kadan, Madureira, Wang \& Zach, 2009). Some analysts with many retail clients have even been demonstrated to be overly positive more often than analysts employed by institutional clients (Cowen, Groysberg \& Healy, 2006).

Prayag and Van Rensburg (2006) researched the distribution of buy, hold and sell recommendations and the impact of recommendations. They considered the March 2000 to April 2003 period and grouped 5282 consensus recommendations into month-end buy, hold and sell portfolios. The percentage of buys and holds were 38 per cent and 59 per cent respectively. The percentage of sell recommendations was only three per cent (consistent with Bidwell, 1977; Elton, Gruber \& Grossman, 1986; Womack, 1996; Barber et al., 2001; Hall \& Millard, 2002).

Analysts who work at brokerages that mainly issue recommendations to retail clients are commonly more positive than those working at companies who do research for institutional and larger corporate clients (Cowen et al., 2006). Again, the fee- and 
incentivisation structures were found to play a significant role in the degree of analyst-positivity portrayed through the recommendations and reports they issued.

Although the general impact of analyst recommendations for JSE-listed shares was confirmed by Hall and Millard (2002), Prayag and Van Rensburg (2006) and Gerritsen and Lötter (2014), none of these studies provide in-depth details concerning the behavioural differences among the individual analysts in the way they issue recommendations, except for claims concerning an overall positive bias stemming from a judgement on non-parametric proportional data.

\section{Overview}

Previous studies on the impact of analyst recommendations in South Africa have only yielded insight into the respective overall sample's distribution of buy, hold and sell recommendations, the impact of consensus recommendation levels and the average impact of recommendations over specific time periods. There is therefore an opportunity to further research analysts' issuance patterns and possible biases among analysts collectively and individually. The literature review further showed that analyst recommendations can generate abnormal returns, but that the impact of the various analysts' recommendations was not equal for all analysts and sectors covered. The analysts' behaviour is suggested to be influenced by their relationships and affiliations, in turn causing a positive bias. The research questions flowing from the literature are formulated as propositions and hypotheses in the methodology section to follow.

\section{$4 \quad$ Data and methodology}

The Thomson Reuters Institutional Brokers' Estimates System (I/B/E/S), which lists recommendations on a day-to-day basis, was used as the primary source of recommendations for this study, and the data was analysed using Microsoft Excel and Visual Basic for Applications (VBA). Recommendations for JSE listed shares were first captured in I/B/E/S from 1993, and this paper analyses the 30486 recommendation initiations and revisions that were issued from 1993 to 2011. The number of active equity analysts and brokerage houses amounted to 901 and 105 respectively over the sample period. I/B/E/S used a five-point scale from ' 1 ' to ' 5 ', where ' 1 ', ' 2 ', ' 3 ', ' 4 ' and ' 5 ' respectively represents a strong buy, a buy, a hold, a sell and a strong sell.

In this section the hypotheses and propositions identified from the existing literature are listed, followed by a brief description of the test(s) related to the specific hypothesis or proposition. 
Descriptive statistics per calendar year for 1993 to 2011 were calculated to measure the distribution of analyst recommendations and the recommendation preferences of the analysts over time. The number of instances for each of the five-point recommendation categories was calculated over the full period and per calendar year to prepare the data for tests that aimed to determine if a tendency existed among analysts to be overly-positive. The results were then presented as percentages of total recommendations per year (e.g. 25 per cent strong sells) to determine if issuance patterns persisted over time and through different market cycles. Correlations were calculated using these proportional annual percentages to measure the analysts' preference for migrating between recommendation categories.

The recommendation categories were collapsed and grouped as buys, holds and sells; and the percentage of total recommendations of each grouping calculated per calendar year. The correlations between buys and sells, buys and holds, and hold and sells were calculated over various control periods: over the total period, years where buys decreased, years where sells decreased, years where buys increased, and lastly, years where sells increased.

Hypothesis 2: Analysts issue more strong sell- and sell recommendations during times of negative sentiment or economic contraction than during times of positive sentiment or economic expansion.

The proportional percentage of total recommendations for each of the five recommendation categories were calculated and allocated to periods of general 'business confidence' (economic expansion) and 'lack of confidence' (economic contraction) to measure if a possible general positive bias persisted among analysts over these periods. The Rand Merchant Bank (RMB) and Bureau for Economic Research's (BER) Business Confidence Index (BCI) was used as an indication of the periods where sentiment was positive or negative (BER, 2014), while the Business cycle phases of South Africa report by the South African Reserve Bank (SARB) was used to indicate the business cycle phase that the listed companies found themselves in (SARB, 2014).

The BCI takes the 'business confidence' of respondents from the retail-, wholesale, motor trade-, manufacturing-, building- and construction sectors into account and measures business confidence at the end of every quarter. The BCI is regarded as a leading indicator of the economic business cycle phases because sentiment is expected to change before it is reflected in the various sectors' reported performance numbers. The RMB/BER's BCI is therefore an suitable indicator of sentiment for the majority of companies the analysts issued recommendations for, and the sentiment 
reflected by the level of the $\mathrm{BCI}$ is expected to coincide with sentiment changes among analysts.

The BCI can range from zero to 100 , with a level above 55 normally viewed as positive sentiment and a level below 45 viewed as negative sentiment (Kershof, 2000). For the purposes of this study, a BCI level above 60 (below 40) was used as an indication of positive sentiment (negative sentiment) to assure a strong indication of general sentiment. The start- and end dates of the business sentiment and economic growth phases, as applicable to the 1993 to 2011 sample period used in this study, are shown in Table 1 Panel A and Panel B respectively.

Table 1: Turning points signalling economic sentiment and growth phases (1993-2011)

\begin{tabular}{l|l|r|l|l|r}
\hline \multicolumn{2}{l}{ Panel A: BCI turning points signalling economic sentiment } \\
\hline Negative sentiment (BCI < 40) & \multicolumn{2}{l}{ Positive sentiment (BCI > 60) } \\
\hline Start & End & $\begin{array}{l}\text { Duration } \\
\text { (days) }\end{array}$ & Start & End & $\begin{array}{l}\text { Duration } \\
\text { (days) }\end{array}$ \\
\hline $1993 / 11 / 01$ & $1994 / 03 / 31$ & 150 & $1994 / 10 / 01$ & $1995 / 06 / 30$ & 272 \\
\hline $1996 / 07 / 01$ & $1996 / 09 / 30$ & 91 & $1995 / 10 / 01$ & $1995 / 12 / 31$ & 91 \\
\hline $1997 / 04 / 01$ & $1999 / 12 / 31$ & 1004 & $2002 / 04 / 01$ & $2002 / 12 / 31$ & 274 \\
\hline $2000 / 04 / 01$ & $2001 / 09 / 30$ & 547 & $2003 / 10 / 01$ & $2007 / 12 / 31$ & 1552 \\
\hline $2008 / 07 / 01$ & $2009 / 12 / 31$ & 548 & & \multicolumn{2}{c}{} \\
\hline $2010 / 04 / 01$ & $2010 / 06 / 30$ & 90 & & & \\
\hline $2011 / 07 / 01$ & $2011 / 12 / 31$ & 183 & & &
\end{tabular}

\begin{tabular}{l|l|l|l|l|l}
\hline \multicolumn{6}{l}{ Panel B: Economic turning points signalling contraction or expansion } \\
\hline Economic contraction & \multicolumn{2}{l|}{ Economic expansion } \\
\hline Start & End & $\begin{array}{l}\text { Duration } \\
\text { (days) }\end{array}$ & Start & End & $\begin{array}{l}\text { Duration } \\
\text { (days) }\end{array}$ \\
\hline & & & $1993 / 06 / 01$ & $1996 / 11 / 30$ & 1125 \\
\hline $1996 / 12 / 01$ & $1999 / 08 / 31$ & 1003 & $1999 / 09 / 01$ & $2007 / 11 / 31$ & 3012 \\
\hline $2007 / 12 / 01$ & $2009 / 08 / 31$ & 639 & $2009 / 09 / 01$ & $2011 / 12 / 31$ & 851 \\
\hline
\end{tabular}

Source: Adapted from BER, 2014 and SARB, 2014

The total number of recommendations and the number of recommendations per recommendation category were counted for each positive and negative sentiment period and for the total period. The percentage incidence of each recommendation category was then calculated within the relevant sentiment's timeframe. The results were further summarised by grouping strong buys and buys together under 'Buys', and sells and strong sells under 'Sells'. The minimum, maximum and weighted average of each recommendation category's percentage incidence per sentimentperiod were lastly calculated for the positive and negative periods respectively in order to measure if analysts communicated an overly-positive sentiment. The z-test 
for proportions was applied to measure if the various recommendation categories' incidence changed significantly.

Hypothesis 3: Analysts do not issue recommendations according to uniform patterns.

The prevalence of analysts' recommendation patterns and preferences were identified and measured. The number of analysts who issued recommendations per recommendation pattern, the instances of recommendations per recommendation category and the average analyst activity per pattern were calculated. The results were then ranked according to average analyst activity per pattern to find the patterns with the most active analysts.

Hypothesis 4: Buys (sells) had a greater impact during positive (negative) sentiment periods than during negative (positive) sentiment periods.

Firstly, the Thomson Reuters Datastream total return share price indices from were used to calculate returns including the effect of dividends for individual shares. Both Datastream and I/B/E/S hold delisted share's data, making the study free of any survivorship bias. The average number of shares covered by analysts was below 150 before 1996 whereafter it increased to 340 in 1999. In the years thereafter the coverage fluctuated between 150 and 200 shares untill 2011.

The short-term market-adjusted return (MAR) and the Fama-French three-factor (Fama \& French, 1992) risk-adjusted return (RAR) impact of each individual analyst's recommendations were calculated as recommended by Gerritsen and Lötter (2014) for the day of and the day after each recommendation was issued. The abnormal returns (ARs) for MAR and RAR on both day $t$ and day $t+1$ were winsorised at their respective first and $99^{\text {th }}$ percentiles to limit the effect of outliers on the results. After winsorisation the MAR and RAR on day $t$ and day $t+1$ all fell within the $-8,7$ per cent to 8,8 per cent range. The term 'impact' is used throughout to describe the abnormal return following recommendations.

The short term impact of the recommendations was used in an attempt to isolate the recommendation and coinciding related information flows from 'noise' that might influence investors over time. For each recommendation category, the negative sentiment period's average MAR and average RAR were subtracted from the positive sentiment period's respective average MAR and RAR for day $t$ and day $t+1$. The statistical significance of the differences was tested with a one-sided t-test for unequal samples with unequal variances. This test was suitable because the sample sizes were large enough for the central limit theorem to hold throughout, especially after the winsorisation reduced the length of each ARs' distribution's tails. 
The results of the analysis of JSE focused equity analysts' recommendation issuance patterns and the impact of their recommendations on the JSE-listed shares are presented and discussed. The distribution of all recommendations per calendar year is presented in Figure 1.

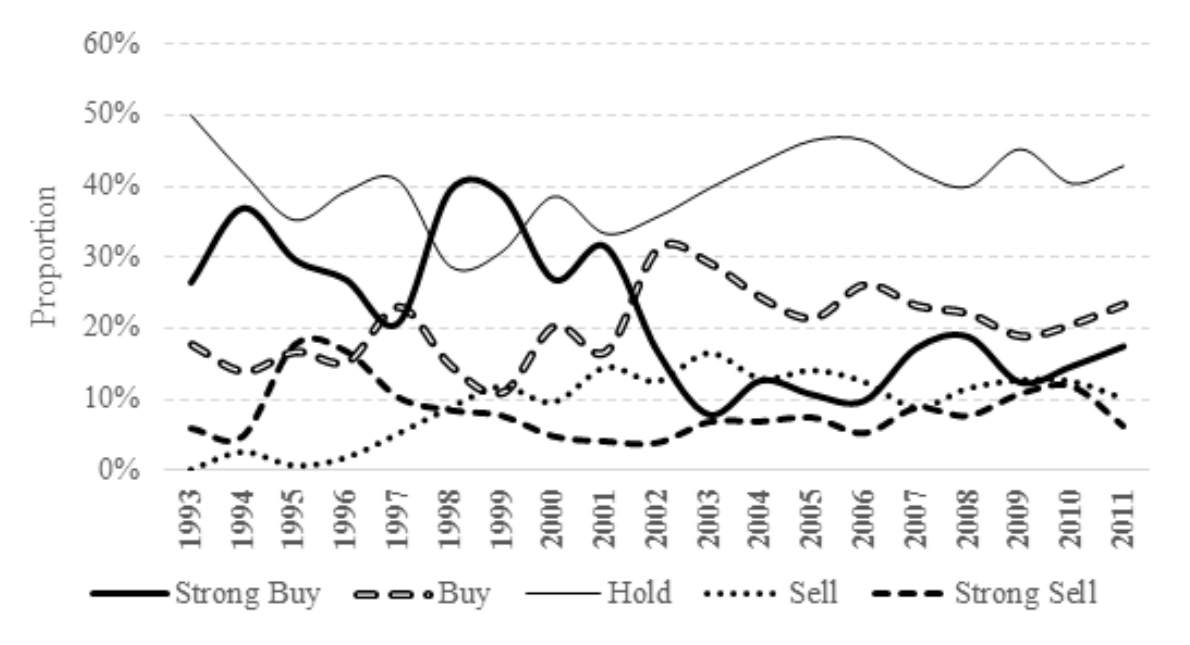

\section{Figure 1: Distribution of recommendations}

The overall 1993 to 2011 distribution among each year's proportion of strong buy-, buy-, hold-, sell- and strong sell recommendations were 24,6 per cent, 19,5 per cent, 37,4 per cent, 10,6 per cent and 7,8 per cent respectively. When differentiating between positive and negative recommendations, the sample consisted of 44,2 per cent positive recommendations versus only 18,4 per cent sell and strong sell recommendations on average.

Analysts migrated between strong buy- and buy recommendations over the period, producing a clear inverse movement between the two recommendation categories in Figure 1. The correlation between the strong buy category's annual percentage incidence and buy category's annual percentage incidence was significant at $0,84^{* * *}$, showing that the active groups of analysts issued recommendations in one of the two categories but not both, also indicative of 'herding' among the analysts (Scharfstein \& Stein, 1990; Trueman, 1994; Jegadeesh \& Kim, 2010).

Positive recommendations reached a level of 32,1 per cent during 2005 , i.e. 10,3 per cent below their average proportion. The decrease in positive recommendations did not have the expected inverse effect on negative recommendations, but rather an 
increase in hold recommendations. Negative recommendations only peaked at 24,4 per cent during 2010, five years after the low-point for positive recommendations. The subsequent eight per cent fall in negative recommendations to 16,3 per cent during 2011 coincided with a five per cent rise in positive recommendations. The correlation analysis indicating the analysts' preferred recommendation categories to migrate to during different market cycles is presented in Table 2.

Table 2: Correlation between recommendation category increases and decreases per calendar year

\begin{tabular}{l|r|c|c|c}
\hline Control period (Scenario) & $\mathbf{n}$ & Buys vs. Sells & Buys vs. Holds & Holds vs. Sells \\
\hline Total period & 18 & $\begin{array}{c}-0,66^{* * *} \\
(-2,97)\end{array}$ & $\begin{array}{c}-0,81^{* * *} \\
(-5,56)\end{array}$ & $\begin{array}{c}0,09 \\
(-0,36)\end{array}$ \\
\hline (a) Decrease in Buys & 9 & $\begin{array}{l}-0,78^{* * *} \\
(-5,00)\end{array}$ & $\begin{array}{c}-0,93 * * * \\
(-9,90)\end{array}$ & $\begin{array}{c}0,49 * * \\
(2,25)\end{array}$ \\
\hline (b) Decrease in Sells & 7 & $\begin{array}{l}-0,78^{* * *} \\
(-5,06)\end{array}$ & $\begin{array}{c}-0,95 * * * \\
(-12,15)\end{array}$ & $\begin{array}{c}0,55^{* * *} \\
(2,65)\end{array}$ \\
\hline (c) Increase in Buys & 9 & $\begin{array}{l}-0,58^{* * *} \\
(-2,82)\end{array}$ & $\begin{array}{c}-0,73^{* * *} \\
(-4,26)\end{array}$ & $\begin{array}{c}-0,14 \\
(-0,57)\end{array}$ \\
\hline (d) Increase in Sells & \multirow{2}{*}{11} & $\begin{array}{c}-0,71^{* * *} \\
(-4,00)\end{array}$ & $\begin{array}{c}-0,81^{* * *} \\
(-5,61)\end{array}$ & $\begin{array}{c}0,17 \\
(0,67)\end{array}$ \\
\hline
\end{tabular}

Note: Correlations indicated with asterisks are significantly different from zero for a two-tailed test.

For the total period, the $-0,81$ and $-0,66$ correlations indicated that analysts predominantly fluctuated between positive and hold recommendation categories and between positive and negative recommendation categories, while the tendency to move between sells and holds was not statistically significant and directionless with a correlation of 0,09 . The years where all buys or all sells increased (scenarios $\mathrm{c}$ and d) also had no correlated movement between hold and sell proportions.

When comparing the years when buys decreased (a) to the years where sells decreased (b), the migration towards hold recommendations from the non-controlled recommendation category was different for the two scenarios with statistically significant correlations of 0,49 and $-0,95$ respectively. This results from (a) and (b) confirm that analysts grouped hold recommendations with sell recommendations, possibly supporting the premise that hold recommendations may be used by analysts to 'cloak' or hide negative opinions at times. In other words, this phenomenon might have been produced by analysts who issued hold recommendations rather than sells during periods of negative sentiment.

While scenarios (a) and (b) produced a statistically significant relationship between the hold and sell categories, holds and sell did not have a significant correlation in (c) and (d) where the controlled recommendation category increased. This might 
have occurred due to strong sentiment from analysts during periods where they increased their issuances of the control variable.

When comparing years where buys increased (c) or decreased (a), hold recommendations showed a stronger negative correlation with buys than with sells did in both scenarios. This result further shows analysts' preference to move to hold than to sells because the two non-controlled recommendation categories should rise and fall in tandem if holds and sells were equally likely as a category. This evidence supports Proposition 1's notion that analysts prefer to issue hold recommendations rather than sell recommendations.

The incidence percentages of the various recommendation categories over different positive and negative business confidence periods and economic growth-phases are displayed in Table 3 and Table 4 respectively.

Table 3: Sentiment of analysts vs. business confidence

\begin{tabular}{|c|c|c|c|c|c|c|c|c|c|c|c|}
\hline \multicolumn{4}{|c|}{ Negative sentiment $(\mathrm{BCI}<40)$} & \multicolumn{5}{|c|}{ Recommendations category } & \multicolumn{3}{|c|}{ Summary } \\
\hline Start & End & Days & Recommendations (n) & $\begin{array}{c}\text { Strong } \\
\text { buy }\end{array}$ & Buy & Hold & Sell & Strong sell & Buys & Holds & Sells \\
\hline 1993/11/01 & $1994 / 03 / 31$ & 151 & 206 & $32,5 \%$ & $10,7 \%$ & $49,5 \%$ & $2,4 \%$ & $4,9 \%$ & $43,2 \%$ & $49,5 \%$ & $7,3 \%$ \\
\hline 1996/07/01 & $1996 / 09 / 30$ & 92 & 274 & $15,7 \%$ & $23,7 \%$ & $47,1 \%$ & $5,5 \%$ & $8,0 \%$ & $39,4 \%$ & $47,1 \%$ & $13,5 \%$ \\
\hline 1997/04/01 & $1999 / 12 / 31$ & 1005 & 10001 & $35,8 \%$ & $14,7 \%$ & $31,6 \%$ & $9,5 \%$ & $8,4 \%$ & $50,5 \%$ & $31,6 \%$ & $17,9 \%$ \\
\hline $2000 / 0401$ & $2001 / 09 / 30$ & 548 & 3269 & $30,3 \%$ & $16,3 \%$ & $36,7 \%$ & $11,8 \%$ & $5,0 \%$ & $46,6 \%$ & $36,7 \%$ & $16,7 \%$ \\
\hline $2008: 07 / 01$ & $2009 / 12 / 31$ & 549 & 2139 & $14,4 \%$ & $19,0 \%$ & $43,9 \%$ & $12,5 \%$ & $10,2 \%$ & $33,3 \%$ & $43,9 \%$ & $22,7 \%$ \\
\hline 2010,0401 & $2010 / 06 / 30$ & 91 & 277 & $18,1 \%$ & $19,9 \%$ & $38,6 \%$ & $11,6 \%$ & $11,9 \%$ & $37,9 \%$ & $38,6 \%$ & $23,5 \%$ \\
\hline \multirow{4}{*}{$2011 / 07 / 01$} & $2011 / 12 / 31$ & 184 & 496 & $20,6 \%$ & $20,4 \%$ & $42,9 \%$ & $10,5 \%$ & $5,6 \%$ & $40,9 \%$ & $42,9 \%$ & $16,1 \%$ \\
\hline & & & Minimum: & $14,4 \%$ & $10,7 \%$ & $31,6 \%$ & $2,4 \%$ & $4,9 \%$ & $33,3 \%$ & $31,6 \%$ & $7,3 \%$ \\
\hline & & & Maximum: & $35,8 \%$ & $23,7 \%$ & $49,5 \%$ & $12,5 \%$ & $11,9 \%$ & $50,5 \%$ & $49,5 \%$ & $23,5 \%$ \\
\hline & & & Weighted average: & $30,8 \%$ & $15,9 \%$ & $35,1 \%$ & $10,3 \%$ & $7,9 \%$ & $46,8 \%$ & $35,1 \%$ & $18,1 \%$ \\
\hline \multicolumn{4}{|c|}{ Positive sentiment $(\mathrm{BCI}>60)$} & \multicolumn{5}{|c|}{ Recommendations category } & \multicolumn{3}{|c|}{ Summary } \\
\hline Start & End & Days & Recommendations (n) & $\begin{array}{c}\begin{array}{c}\text { Strong } \\
\text { buy }\end{array} \\
\text { nat }\end{array}$ & Buy & Hold & Sell & Strong sell & Buys & Holds & Sells \\
\hline 1994/10:01 & $1995 / 06 / 30$ & 273 & 111 & $59,5 \%$ & $1,8 \%$ & $28,8 \%$ & $0,9 \%$ & $9,0 \%$ & $61,3 \%$ & $28,8 \%$ & $9,9 \%$ \\
\hline 1995/10/01 & $1995 / 12 / 31$ & 92 & 322 & $15,5 \%$ & $25,2 \%$ & $36,0 \%$ & $0,6 \%$ & $22,7 \%$ & $40,7 \%$ & $36,0 \%$ & $23,3 \%$ \\
\hline $2002 / 04 / 01$ & $2002 / 12 / 31$ & 275 & 1326 & $14,4 \%$ & $32,8 \%$ & $36,2 \%$ & $12,7 \%$ & $3,8 \%$ & $47,2 \%$ & $36,2 \%$ & $16,6 \%$ \\
\hline $2003 / 10: 01$ & $2007 / 12 / 31$ & 1553 & 5083 & $12,5 \%$ & $23,6 \%$ & $44,5 \%$ & $12,3 \%$ & $7,0 \%$ & $36,2 \%$ & $44,5 \%$ & $19,3 \%$ \\
\hline & & & Minimum: & $12,5 \%$ & $1,8 \%$ & $28,8 \%$ & $0,6 \%$ & $3,8 \%$ & $36,2 \%$ & $28,8 \%$ & $9,9 \%$ \\
\hline & & & Maximum: & $59,5 \%$ & $32,8 \%$ & $44,5 \%$ & $12,7 \%$ & $22,7 \%$ & $61,3 \%$ & $44,5 \%$ & $23,3 \%$ \\
\hline & & & Weighted average: & $13,8 \%$ & $25,1 \%$ & $42,2 \%$ & $11,7 \%$ & $7,2 \%$ & $38,9 \%$ & $42,2 \%$ & $18,8 \%$ \\
\hline
\end{tabular}


Table 4: Sentiment of analysts vs. economic cycles

\begin{tabular}{|c|c|c|c|c|c|c|c|c|c|c|c|}
\hline \multicolumn{4}{|c|}{ Negative cycle - contraction } & \multicolumn{5}{|c|}{ Recommendation category } & \multicolumn{3}{|c|}{ Summary } \\
\hline Start & End & Days & Recommendations ( $\mathrm{n}$ ) & Strong buy & Buy & Hold & Sell & Strong sell & Buys & Holds & Sells \\
\hline $1996 / 12 / 01$ & \begin{tabular}{|l|}
$1999 / 08 / 31$ \\
\end{tabular} & 1004 & 9523 & $35,7 \%$ & $14,6 \%$ & $31,9 \%$ & $9,1 \%$ & $8,7 \%$ & $50,3 \%$ & $31,9 \%$ & $17,8 \%$ \\
\hline \multirow[t]{4}{*}{$2007 / 12 / 01$} & \begin{tabular}{|l|}
$2009 / 08 / 31$ \\
\end{tabular} & 640 & 2279 & $16,4 \%$ & $19,7 \%$ & $42,5 \%$ & $11,9 \%$ & $9,4 \%$ & $36,1 \%$ & $42,5 \%$ & $21,4 \%$ \\
\hline & & & Minimum: & $16,4 \%$ & $14,6 \%$ & $31,9 \%$ & $\begin{array}{l}9,1 \% \\
\end{array}$ & $8,7 \%$ & $36,1 \%$ & $31,9 \%$ & $17,8 \%$ \\
\hline & & & Maximum: & $35,7 \%$ & $19,7 \%$ & $42,5 \%$ & $11,9 \%$ & $9,4 \%$ & $50,3 \%$ & $42,5 \%$ & $21,4 \%$ \\
\hline & & & Weighted average: & $32,0 \%$ & $15,6 \%$ & $33,9 \%$ & $9,7 \%$ & $8,9 \%$ & $47,6 \%$ & $33,9 \%$ & $18,5 \%$ \\
\hline \multicolumn{4}{|c|}{ Positive cycle - expansion } & \multicolumn{5}{|c|}{ Recommendation category } & \multicolumn{3}{|c|}{ Summary } \\
\hline Start & End & Days & Recommendations ( $\mathbf{n}$ ) & Strong buy & Buy & Hold & Sell & Strong sell & Buys & Holds & Sells \\
\hline $1993 / 11 / 01$ & \begin{tabular}{|l|}
$1996 / 11 / 30$ \\
\end{tabular} & 1126 & 2048 & $28,6 \%$ & $15,5 \%$ & $39,1 \%$ & $1,6 \%$ & $15,2 \%$ & $44,1 \%$ & $39,1 \%$ & $16,7 \%$ \\
\hline $1999 / 09 / 01$ & $2007 / 11 / 30$ & 3013 & 13778 & $19,7 \%$ & $23,0 \%$ & $39,3 \%$ & $12,4 \%$ & $5,6 \%$ & $42,8 \%$ & $39,3 \%$ & $18,0 \%$ \\
\hline \multirow{4}{*}{$2009 / 09 / 01$} & $2011 / 12 / 31$ & 852 & 2858 & $14,8 \%$ & $22,0 \%$ & $42,1 \%$ & $11,8 \%$ & $9,3 \%$ & $36,8 \%$ & $42,1 \%$ & $21,1 \%$ \\
\hline & & & Minimum: & $14,8 \%$ & $15,5 \%$ & $39,1 \%$ & $1,6 \%$ & $5,6 \%$ & $36,8 \%$ & $39,1 \%$ & $16,7 \%$ \\
\hline & & & Maximum: & $28,6 \%$ & $23,0 \%$ & $42,1 \%$ & $12,4 \%$ & $15,2 \%$ & $44,1 \%$ & $42,1 \%$ & $21,1 \%$ \\
\hline & & & Weighted average: & $20,0 \%$ & $22,0 \%$ & $39,7 \%$ & $11,1 \%$ & $7,2 \%$ & $42,0 \%$ & $39,7 \%$ & $18,3 \%$ \\
\hline
\end{tabular}

A few patterns emerge when comparing Table 3 and Table 4. The individual SARB business cycle periods lasted much longer on average than the sentiment indicator's individual periods. Furthermore, strong buys occurred more frequently than buys before 2002 irrespective of the sentiment- or economic growth cycle direction, while analysts issued more buys than strong buys from 2002 onwards. Strong sells also generally occurred more often before 1997 than after 1997. The hold category was fairly stable over all of the event windows in the two tables, and was six per cent to seven per cent more on average during economic expansion and positive sentiment than during negative cycles. The proportion of all sells was between 18 and 19 per cent in every table, which is markedly higher than the three per cent reported by Prayag and van Rensburg (2006).

The buys, holds and sells summary categories' averages during the economic contraction and negative sentiment periods further only differed by 0,8 per cent, 1,2 per cent and $-0,4$ per cent respectively, indicating a very similar recommendation pattern among analysts for all categories during negative cycles. Conversely, the summary categories' averages during the economic expansion and positive sentiment periods differed by 3,1 per cent, 2,5 per cent and 0,5 per cent respectively, indicating a very similar recommendation pattern only for the sells category. Figure 2 offers a visual depiction of the aforementioned relationship. 


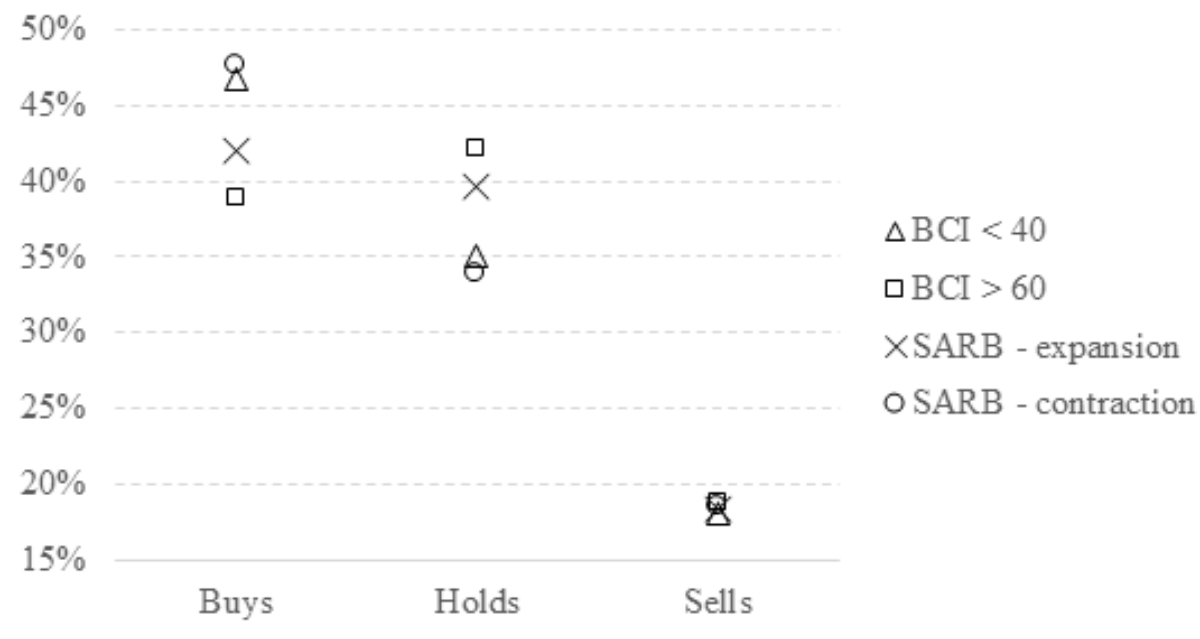

Figure 2: Average buys, holds and sells across sentiment- and economic growth cycles

The number of sells issued by analysts during negative periods overlaps for all four data points in Figure 3.2, while the expectation would have been that percentage sells during ' $\mathrm{BCI}<40$ ' and 'SARB - contraction' would be higher than during 'BCI $>60$ ' and 'SARB - expansion' respectively. The analysts therefore did not issue more negative recommendations during negative cycles. Another unexpected result shown visually is that the percentage buys was less than the percentage holds during positive BCI cycles. One possible explanation could be that the analysts started issuing positive (negative) recommendations before the end of the negative cycles (positive cycles) in anticipation of what was to come; while another reason could have been that the measurement of the cycles by the SARB and the BER respectively lagged the actual cycles experienced by the individual listed shares that received recommendations. The results of the statistical significance tests of the differences between the negative and positive cycles are displayed in Table 5 .

Table 5: Change in category incidence: negative cycles to positive cycles

\begin{tabular}{l|c|c|c}
\cline { 2 - 4 } & \multicolumn{1}{l|}{ Buys } & \multicolumn{1}{l}{ Holds } & \multicolumn{1}{l}{ Sells } \\
\hline Positive sentiment \% minus negative & $-7,9 \% * * *$ & $7,1 \% * * *$ & $0,7 \%$ \\
sentiment \% & $(-11,07)$ & $(10,23)$ & $(1,26)$ \\
\hline \multirow{2}{*}{ Expansion \% minus contraction } & $-5,6 \% * * *$ & $5,8 \% * * *$ & $-0,2 \%$ \\
& $(-9,59)$ & $(10,19)$ & $(-0,44)$ \\
\hline
\end{tabular}

Note: The test-statistic value for the z-test for proportions is indicated in brackets. Differences indicated with asterisks are statistically significant in a two-tailed test of whether the proportions differed significantly among the various periods $\left(\mathrm{P}_{1} \neq \mathrm{P}_{2}\right)$ 
The analysts' recommendation issuance patterns for buys and holds changed significantly over both sentiment and economic cycle tests. The unexpected 0.7 per cent higher incidence of sell recommendations during positive sentiment periods than during negative periods was not statistically significant, while the incidence of sells during both economic contraction and expansion periods was also not statistically significantly different from each other. Analysts are therefore judged to have been overly positive during periods of low business confidence and economic contractions, and exhibited a positive bias. This result leads to the conclusion that the null hypothesis of Hypothesis 2 cannot be rejected, and that analysts did not issue more strong sell- and sell recommendations during times of negative sentiment and economic contraction than during times of positive sentiment and economic expansion. This finding strongly supports the notion of a positive bias among analysts.

Now that the overall migration of analysts' collective recommendation preferences has been investigated, the individual analysts' recommendation issuance patterns will be analysed. The top 15 preferred recommendation categories and pattern distribution of analysts are indicated in Table 6.

The two most common recommendation patterns are ranked first and sixth (13,5 per cent and 15,5 per cent respectively), indicating that almost a third of analysts either issued recommendations throughout the five-point scale or chose to only issue buy-, hold- and sell recommendations. Although analysts only issuing buy-, hold- and sell recommendations are the most prevalent, analysts issuing recommendations from strong buy through to strong sell were the most active over the sample period. Signs of a positive bias are evident throughout Table 6 . Analysts who never issued buyand strong buy recommendations comprised 13,2 per cent of the sample, while 38,6 per cent never issued a sell- and strong sell recommendation. The second most active group of analysts only issued strong buy- to sell recommendations, choosing to not issue strong sell recommendations at all and only issue negative sell recommendations 11,9 per cent of the time. 
Table 6: Top-15 recommendation pattern activity distributions (1993-2011)

\begin{tabular}{|c|c|c|c|c|c|c|c|}
\hline & $\begin{array}{l}\text { Strong } \\
\text { buy }\end{array}$ & Buy & Hold & Sell & $\begin{array}{l}\text { Strong } \\
\text { sell }\end{array}$ & $\begin{array}{l}\text { Average of } \\
\text { analysts' } \\
\text { total } \\
\text { activity }\end{array}$ & $\begin{array}{l}\text { Proportion } \\
\text { of analysts } \\
\text { following } \\
\text { pattern }\end{array}$ \\
\hline \multirow{15}{*}{ 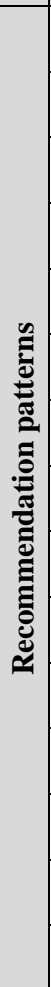 } & $\begin{array}{r}4835 \\
(28,2 \%)\end{array}$ & $\begin{array}{r}2965 \\
(17,3 \%)\end{array}$ & $\begin{array}{r}5955 \\
(34,7 \%)\end{array}$ & $\begin{array}{r}1853 \\
(10,8 \%)\end{array}$ & $\begin{array}{l}1557 \\
(9,1 \%)\end{array}$ & 133 & $13,5 \%$ \\
\hline & $\begin{array}{l}384 \\
(18,2 \%)\end{array}$ & $\begin{array}{l}673 \\
(31,9 \%)\end{array}$ & $\begin{array}{l}800 \\
(38 \%)\end{array}$ & $\begin{array}{l}251 \\
(11,9 \%)\end{array}$ & & 47 & $4,7 \%$ \\
\hline & & $\begin{array}{l}125 \\
(31,8 \%)\end{array}$ & $\begin{array}{l}179 \\
(45,5 \%)\end{array}$ & $\begin{array}{l}71 \\
(18,1 \%)\end{array}$ & $\begin{array}{l}18 \\
(4,6 \%)\end{array}$ & 44 & $0,9 \%$ \\
\hline & $\begin{array}{l}671 \\
(34,3 \%)\end{array}$ & $\begin{array}{l}292 \\
(14,9 \%)\end{array}$ & $\begin{array}{l}763 \\
(39 \%)\end{array}$ & & $\begin{array}{l}228 \\
(11,7 \%)\end{array}$ & 41 & $5,0 \%$ \\
\hline & $\begin{array}{l}827 \\
(38,4 \%)\end{array}$ & & $\begin{array}{l}917 \\
(42,6 \%)\end{array}$ & & $\begin{array}{l}407 \\
(18,9 \%)\end{array}$ & 28 & $8,1 \%$ \\
\hline & & $\begin{array}{r}1397 \\
(35,6 \%)\end{array}$ & $\begin{array}{l}1707 \\
(43,5 \%)\end{array}$ & $\begin{array}{l}817 \\
(20,8 \%)\end{array}$ & & 27 & $15,5 \%$ \\
\hline & $\begin{array}{l}128 \\
(37,4 \%)\end{array}$ & & $\begin{array}{l}159 \\
(46,5 \%)\end{array}$ & $\begin{array}{l}55 \\
(16,1 \%)\end{array}$ & & 19 & $1,9 \%$ \\
\hline & & $\begin{array}{l}67 \\
(48,2 \%)\end{array}$ & $\begin{array}{l}44 \\
(31,7 \%)\end{array}$ & & $\begin{array}{l}28 \\
(20,1 \%)\end{array}$ & 12 & $1,3 \%$ \\
\hline & $\begin{array}{l}73 \\
(30,9 \%)\end{array}$ & $\begin{array}{l}75 \\
(31,8 \%)\end{array}$ & $\begin{array}{l}88 \\
(37,3 \%)\end{array}$ & & & 11 & $2,3 \%$ \\
\hline & $\begin{array}{l}50 \\
(64,9 \%)\end{array}$ & & & & $\begin{array}{l}27 \\
(35,1 \%)\end{array}$ & 9 & $0,9 \%$ \\
\hline & $\begin{array}{c}9 \\
(69,2 \%) \\
\end{array}$ & & & $\begin{array}{c}4 \\
(30,8 \%) \\
\end{array}$ & & 7 & $0,2 \%$ \\
\hline & & $\begin{array}{l}244 \\
(50,1 \%)\end{array}$ & $\begin{array}{l}243 \\
(49,9 \%)\end{array}$ & & & 6 & $8,4 \%$ \\
\hline & $\begin{array}{l}143 \\
(50,5 \%)\end{array}$ & & $\begin{array}{l}140 \\
(49,5 \%)\end{array}$ & & & 5 & $5,8 \%$ \\
\hline & & & $\begin{array}{c}9 \\
(36 \%)\end{array}$ & $\begin{array}{c}10 \\
(40 \%)\end{array}$ & $\begin{array}{c}6 \\
(24 \%)\end{array}$ & 5 & $0,5 \%$ \\
\hline & & & $\begin{array}{l}57 \\
(53,3 \%)\end{array}$ & $\begin{array}{l}50 \\
(46,7 \%)\end{array}$ & & 5 & $2,3 \%$ \\
\hline
\end{tabular}

The number of instances per recommendation category is presented; and the percentage occurrence within the pattern displayed in brackets. The list is sorted according to the 'average analyst activity' among individual analysts who issued recommendations according to the pattern. 'Average analyst activity' is the mean number of recommendations per analyst per recommendation pattern. The percentage of analysts who only issued recommendations under a certain pattern is indicated under "Proportion of analysts following pattern".

The third most active analyst group only issued buy- through to strong sell recommendations. Although this group contains two negative recommendation categories and only one positive recommendation category, only 22.7 per cent of this recommendation pattern was negative recommendations, again supporting the notion 
of negative-recommendation aversion among the analysts. All the aforementioned results support the notion in Proposition 3 that analysts did not issue recommendations according to uniform patterns.

Analysts who are positively biased would therefore be expected to rather issue a hold recommendation than a negative recommendation. The abnormal return for hold recommendations should therefore be expected to be slightly negative if the group contains both true hold recommendations and concealed negative opinions.

The two positive and negative periods' abnormal return differentials on the day of and the day after the recommendations for the 1993 tot 2011 period are indicated in Tables 7 and 8 . In both tables the negative sentiment period's returns are subtracted from the positive period's returns to measure if investors reacted more positively or negatively during certain periods than in others.

Table 7: BCI positive minus negative sentiment average abnormal return impact

\begin{tabular}{|c|c|c|c|c|c|c|}
\hline \multirow[b]{2}{*}{$\begin{array}{l}\text { Abnormal } \\
\text { return: }\end{array}$} & & \multicolumn{5}{|c|}{ Recommendation } \\
\hline & & Strong buy & Buy & Hold & Sell & $\begin{array}{l}\text { Strong } \\
\text { sell }\end{array}$ \\
\hline \multirow{3}{*}{$\begin{array}{l}\text { Market- } \\
\text { adjusted }\end{array}$} & Day $\mathbf{t}$ & $\begin{array}{l}0,14 \% \text { ** } \\
(1,734)\end{array}$ & $\begin{array}{c}0,21 \% * * * \\
(2,94)\end{array}$ & $\begin{array}{r}-0,02 \% \\
(-0,373)\end{array}$ & $\begin{array}{c}-0,03 \% \\
(-0,249)\end{array}$ & $\begin{array}{r}-0,10 \% \\
(-0,804)\end{array}$ \\
\hline & Day $t+1$ & $\begin{array}{r}0,09 \% \\
(1,233)\end{array}$ & $\begin{array}{c}0,19 \% * * * \\
(2,533)\end{array}$ & $\begin{array}{r}0,02 \% \\
(0,302)\end{array}$ & $\begin{array}{r}0,05 \% \\
(0,421)\end{array}$ & $\begin{array}{c}-0,29 \% * * * \\
(-2,408)\end{array}$ \\
\hline & Count & $\begin{array}{c}919 \text { vs, } \\
4998 \\
\end{array}$ & $\begin{array}{c}1666 \mathrm{vs}, \\
2579\end{array}$ & $\begin{array}{c}2794 \text { vs, } \\
5623\end{array}$ & $\begin{array}{c}762 \text { vs, } \\
1636 \\
\end{array}$ & $\begin{array}{r}471 \text { vs, } \\
1263 \\
\end{array}$ \\
\hline \multirow{3}{*}{$\begin{array}{l}\text { Risk- } \\
\text { adjusted }\end{array}$} & Day $\mathbf{t}$ & $\begin{array}{c}0,10 \% * \\
(1,282)\end{array}$ & $\begin{array}{r}0,09 \% \\
(1,248)\end{array}$ & $\begin{array}{l}-0,03 \% \\
(-0,49)\end{array}$ & $\begin{array}{r}-0,02 \% \\
(-0,228)\end{array}$ & $\begin{array}{r}-0,08 \% \\
(-0,681)\end{array}$ \\
\hline & Day $t+1$ & $\begin{array}{l}-0,02 \% \\
(-0,21)\end{array}$ & $\begin{array}{l}0,12 \% * \\
(1,61)\end{array}$ & $\begin{array}{r}-0,02 \% \\
(-0,405)\end{array}$ & $\begin{array}{r}-0,01 \% \\
(-0,082)\end{array}$ & $\begin{array}{l}-0,28 \% * * \\
(-2,300)\end{array}$ \\
\hline & Count & $\begin{array}{r}884 \text { vs, } \\
4839\end{array}$ & $\begin{array}{r}1624 \mathrm{vs}, \\
2489\end{array}$ & $\begin{array}{r}2710 \mathrm{vs}, \\
5468\end{array}$ & $\begin{array}{c}742 \text { vs, } \\
1601\end{array}$ & $\begin{array}{r}459 \text { vs, } \\
1241\end{array}$ \\
\hline
\end{tabular}

Note: Abnormal returns indicated with asterisks are significant in a one-tailed test of whether the mean abnormal return difference is significantly different from zero. 
Table 8: Expansion minus contraction average abnormal return impact

\begin{tabular}{|c|c|c|c|c|c|c|}
\hline \multirow[b]{2}{*}{$\begin{array}{l}\text { Abnormal } \\
\text { return: }\end{array}$} & & \multicolumn{5}{|c|}{ Recommendation } \\
\hline & & $\begin{array}{l}\text { Strong } \\
\text { buy }\end{array}$ & Buy & Hold & Sell & $\begin{array}{l}\text { Strong } \\
\text { sell }\end{array}$ \\
\hline \multirow{3}{*}{$\begin{array}{l}\text { Market- } \\
\text { adjusted }\end{array}$} & Day t & $\begin{array}{r}0,06 \% \\
(0,876)\end{array}$ & $\begin{array}{r}0,03 \% \\
(0,386)\end{array}$ & $\begin{array}{r}-0,03 \% \\
(-0,499)\end{array}$ & $\begin{array}{l}-0,18 \% * \\
(-1,68)\end{array}$ & $\begin{array}{r}-0,02 \% \\
(-0,212)\end{array}$ \\
\hline & $\begin{array}{l}\text { Day } \\
t+1\end{array}$ & $\begin{array}{r}0,05 \% \\
(0,776) \\
\end{array}$ & $\begin{array}{r}0,01 \% \\
(0,098) \\
\end{array}$ & $\begin{array}{r}-0,03 \% \\
(-0,535) \\
\end{array}$ & $\begin{array}{l}-0,15 \% * \\
(-1,405) \\
\end{array}$ & $\begin{array}{l}-0,14 \% * \\
(-1,290) \\
\end{array}$ \\
\hline & Count & $\begin{array}{c}3647 \mathrm{vs}, \\
3726\end{array}$ & $\begin{array}{c}4007 \text { vs, } \\
1806\end{array}$ & $\begin{array}{c}7195 \mathrm{vs}, \\
3911 \\
\end{array}$ & $\begin{array}{c}1993 \mathrm{vs}, \\
1086\end{array}$ & $\begin{array}{c}1288 \text { vs, } \\
1014\end{array}$ \\
\hline \multirow{3}{*}{ Risk-adjusted } & Day t & $\begin{array}{l}0,09 \% * \\
(1,335)\end{array}$ & $\begin{array}{r}-0,05 \% \\
(-0,648) \\
\end{array}$ & $\begin{array}{r}-0,01 \% \\
(-0,212) \\
\end{array}$ & $\begin{array}{r}-0,02 \% \\
(-0,186) \\
\end{array}$ & $\begin{array}{r}-0,02 \% \\
(-0,164) \\
\end{array}$ \\
\hline & $\begin{array}{l}\text { Day } \\
t+1\end{array}$ & $\begin{array}{r}0,04 \% \\
(0,616)\end{array}$ & $\begin{array}{r}-0,03 \% \\
(-0,456)\end{array}$ & $\begin{array}{r}-0,04 \% \\
(-0,806)\end{array}$ & $\begin{array}{l}-0,17 \% * \\
(-1,585)\end{array}$ & $\begin{array}{r}-0,12 \% \\
(-1,157)\end{array}$ \\
\hline & Count & $\begin{array}{c}3512 \mathrm{vs}, \\
3598\end{array}$ & $\begin{array}{c}3878 \text { vs, } \\
1738 \\
\end{array}$ & $\begin{array}{c}6975 \mathrm{vs}, \\
3800 \\
\end{array}$ & $\begin{array}{c}1940 \mathrm{vs}, \\
1065\end{array}$ & $\begin{array}{l}1253 \text { vs, } \\
997\end{array}$ \\
\hline
\end{tabular}

abnormal return difference is significantly different from significan.

The results in Table 7 contains five instances of strong statistically significant differences in investor's reaction to analysts' recommendations, with both buy categories and strong sells showing a marked difference in the average impact of recommendations when comparing periods of high and low business confidence. Strong buys reacted stronger on the day the recommendation was issued, strong sells performed better the day after the recommendation was issued during low confidence periods, and buys performed much stronger on both days when adjusted for the market.

The results in Table 8 are weakly significant at the $10 \%$ level at best. Of all the recommendation categories, sell recommendations performed the best during economic contractions when compared to performance during economic expansions. Although not statistically significant, the other results in Table 8 do have the correct expected sign with buys doing better on average during expansions, and holds and sells having a greater average impact during contractions.

When comparing Tables 7 and 8, the demarcation of investor sentiment and their subsequent reaction to recommendations fared much better when using the BER's BCI than when relying on the SARB's economic cycle indicators. The null hypothesis of Hypothesis 4 can therefore be rejected only when using the BCI, indicating that the impact of recommendations increased when aligned with the prevailing sentiment in the market. The use of the SARB's economic cycle index is therefore not advised when trying to match investor sentiment to the sentiment of analysts. 
This study investigated the proposition of previous studies that analysts issuing recommendations on JSE-listed shares may be overly positive in their reported opinions, and continued to research the patterns of issuance preferences among analysts as well as the differential impact on prices when comparing positive to negative sentiment periods.

The result that supported this notion of a positive bias the strongest was where analysts on average did not change the proportion of negative recommendations during periods of market contraction or low business confidence when compared to periods where analysts were expected to be bullish. Analysts also seemed to have a similar preference to issue both hold and sell recommendations, and would rather move from buy to hold than from sell to hold.

Only 13.5 per cent of analysts issued recommendations through all categories from strong buy through to strong sell, while the other analysts opted for differing recommendation patterns. The analysts therefore did not react uniformly, and exhibited dissimilarities in their recommendation issuance behaviour. Individual investors who intend on following an analyst or analysts should therefore be aware that analysts might react differently from each other to the same information, in line with the 'differences of opinion' theory (Harris \& Raviv, 1993). Investors are therefore advised to study an analysts' historic recommendations in order to be aware of the analyst's preferences in order to align the investor's trades accordingly.

While previous local and international studies measured the average positive bias (strong buy and buy recommendations versus total number of recommendations) over the entire sample, this study investigated a possible positive bias per annum over the entire sample period, during economic growth phase periods, and over periods of high- and low business confidence. The annual distribution of recommendations was used to investigate the flow of positive versus negative recommendations as analyst sentiment changed during different cycles. According to the author's knowledge, no other study has investigated either recommendation 'flow' versus overall analyst sentiment, or the proportional differences during different phases in the economy.

The BER Business Confidence Index and the SARB Business cycle phases of South Africa report were used to infer periods of positive or negative sentiment among investors and analysts alike, and compare the impact of analysts during the two respective sentiment periods. The BCI produced statistically significant results for strong buys, buys, and strong sells that were in line with expectations, while the SARB demarcation yielded only weakly significant results for sell recommendations and strong buy RARs on day t. The BER BCI is therefore concluded to be able to 
capture the short term growth cycles that will be 'ignored' by the SARB's index. The BER BCI may thus contain a stronger alignment of analyst and investor sentiment, and can be used as a proxy for overall increased directional impact of analyst recommendations during periods of positive or negative sentiment.

\section{References}

Asquith, P., Mikhail, M.B. \& Au, A.S. 2005. 'Information content of equity analyst reports', Journal of Financial Economics, 75(2), 245-282.

Barber, B., Lehavy, R., McNichols, M. \& Trueman, B. 2001. 'Can investors profit from the prophets? Security analyst recommendations and stock returns', The Journal of Finance, 56(2), 531-563.

Bidwell, C.M. 1977. 'How good is institutional brokerage research?', Journal of Portfolio Management, 28(1), 26-31.

Boni, L. \& Womack, K.L. 2006. 'Analysts, industries and price momentum', Journal of Financial and Quantitative Analysis, 41(1), 85-109.

Bradshaw, M.T. 2002. 'The use of target prices to justify sell-side analysts' stock recommendations', Accounting Horizons, 16(1), 27-41.

Bureau for Economic Research (BER). 2014. RMB/BER Business Confidence Index: Historical data. [Online] Available: http://www.ber.ac.za/Knowledge/pkDownloadDocument.aspx? docid=6000 Accessed: 16 January 2014 .

Clarke, J., Ferris, S.P., Jayaraman, N. \& Lee, J. 2006. 'Are analyst recommendations biased? Evidence from corporate bankruptcies', Journal of Financial and Quantitative Analysis, 41(1), 169-196.

Cowen, A., Groysberg, B. \& Healy, P. 2006. 'Which types of analyst firms are more optimistic?', Journal of Accounting and Economics, 41(1), 119-146.

Diefenbach, R.E. 1972. 'How good is institutional brokerage research?', Financial Analysts Journal, 28, 54-60.

Elton, E.J., Gruber, M.J. \& Grossman, S. 1986. 'Discrete expectational data and portfolio performance', The Journal of Finance, 41(3), 699-713.

Fama, E.F. \& French, K.R. 1992. 'The cross-section of expected stock returns', The Journal of Finance, 47(2), 427-465.

Fang, L.H. \& Yasuda, A. 2014. Are stars' opinions worth more? The relation between analyst reputation and recommendation values', Journal of Financial Services Research, 46(3), 235-269.

Gerritsen, D.F. \& Lötter, R. 2014. 'The impact of analyst recommendations and revisions on the prices of JSE-listed companies', Investment Analysts Journal, 43(80), 45-57. 
Hall, J.H. \& Millard, S.M. 2002. 'An assessment of the value of brokerage information for individual investors', The Investment Analysts Journal, 55, 45-51.

Harris, M. \& Raviv, A. 1993. 'Differences of opinion make a horse race', The Review of Financial Studies, 6(3), 473-506.

Irvine, P.J. 2001. 'Do analysts generate trade for their firms? Evidence from the Toronto stock exchange', Journal of Accounting and Economics, 30(2), 209-226.

Irvine, P.J. 2004. 'Analysts' forecasts and brokerage-firm trading', The Accounting Review, 79(1), 125-149.

Jegadeesh, N. \& Kim, W. 2010. 'Do analysts herd? An analysis of recommendations and market reactions', Review of Financial Studies, 23(2), 901-937.

Kadan, O., Madureira, L., Wang, R. \& Zach, T. 2009. 'Conflicts of interest and stock recommendations: The effects of the global settlement and related regulations', Review of Financial Studies, 22(10), 4189-4217.

Kerl, A., Stolper, O. \& Walter, A. 2012. 'Tagging the triggers: An empirical analysis of information events prompting sell-side analyst reports', Financial Markets and Portfolio Management, 26(2), 217-246.

Kershof, G. 2000. Measuring business and consumer confidence in South Africa. [Online] Available: http://www.ber.ac.za/Knowledge/pkDownloadDocument.aspx?docid=4128, Accessed: 16 January 2014

Loh, R.K. \& Stulz, R.M. 2011. 'When are analyst recommendation changes influential?', Review of Financial Studies, 24(2), 593-627.

Malmendier, U. \& Shanthikumar, D.M. 2007. 'Are small investors naïve about incentives?', Journal of Financial Economics, 85(2), 457-489.

Mikhail, M.B., Walther, B.R. \& Willis, R.H. 2004. 'Do security analysts exhibit persistent differences in stock picking ability?', Journal of Financial Economics, 74(1), 67-91.

Moshirian, F., Ng, D. \& Wu, E. 2009. 'The value of stock analysts' recommendations: Evidence from emerging markets', International Review of Financial Analysis, 18(1), 74-83.

Peng, L. \& Xiong, W. 2006. 'Investor attention, overconfidence and category learning', Journal of Financial Economics, 80(3), 563-602.

Prayag, C. \& Van Rensburg, P. 2006. 'The value of analysts' consensus recommendations: Evidence from South African brokerage houses’, Investment Analysts Journal, 63, 5-17.

Previts, G.J., Bricker, R.J., Robinson, T.R. \& Young, S.J. 1994. 'A content analysis of sell-side financial analyst company reports’, Accounting Horizons, 8(2), 55-70. 
Savor, P. 2012. 'Stock returns after major price shocks: The impact of information', Journal of Financial Economics, 106(3), 635-659.

Scharfstein, D. \& Stein, J. 1990. 'Herd behavior and investment', American Economic Review, 80(1), 465-479.

Shefrin, H. 2000. Beyond greed and fear: Understanding behavioral finance and the psychology of investing. New York: Oxford University Press.

South African Reserve Bank (SARB). 2014. South African Reserve Bank Quarterly Bulletin December 2014. [Online] Available: https://www.resbank.co.za/Lists/News\%20and\%20 Publications/Attachments/6532/01Full\%20Quarterly\%20Bulletin\%20\%E2\%80\%93\%20Decembe r\%202014.pdf Accessed: 15 January 2014.

Stickel, S.E. 1995. 'The anatomy of the performance of buy and sell recommendations', Financial Analysts Journal, 51(5), 25-39.

Trueman, B. 1994. 'Analyst forecasts and herding behavior', Review of Financial Studies, 7(1), 97 124.

Welch, I. 2000. 'Herding among security analysts', Journal of Financial Economics, 58(3), 369396.

Womack, K.L. 1996. 'Do brokerage analysts' recommendations have investment value?', The Journal of Finance, 51(1), 137-167. 